\title{
Effect of environment conditioning on mode II fracture behaviour of adhesively bonded joints
}

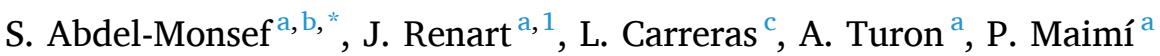 \\ ${ }^{a}$ AMADE, Polytechnic School, University of Girona, Campus Montilivi s/n, 17003 Girona, Spain \\ ${ }^{\mathrm{b}}$ Structural Engineering Dept., Faculty of Engineering, Zagazig University, P.O. Box 44519, Zagazig, Sharkia, Egypt \\ ${ }^{c}$ Dept. of Materials and Production, Aalborg University, Fibigerstraede 16, DK-9220 Aalborg East, Denmark
}

\section{A R T I C L E I N F O}

\section{Keywords:}

ELS

Mode II

Fracture

Bonded joints

Environmental effect

Accelerated ageing

\begin{abstract}
A B S T R A C T
The effect of environmental conditions on the fracture behaviour of two types of adhesively bonded joints (wetaged and non-aged) is experimentally studied under mode II loading. End Loaded Split tests were performed at various temperatures $\left(-55^{\circ} \mathrm{C}\right.$, room temperature $(\mathrm{RT})$ and $\left.80^{\circ} \mathrm{C}\right)$ on non-aged and aged specimens. The nonaged specimens were stored in a laboratory under controlled conditions at RT $\left(23{ }^{\circ} \mathrm{C} / 55 \mathrm{RH}\right)$ while the wetaged specimens were exposed to accelerated ageing in an environmental chamber at $70{ }^{\circ} \mathrm{C} / 85 \% \mathrm{RH}$ for four years. The data reduction was applied using an inverse method and two other direct methods. A good agreement between these methods is observed. The analysis of the obtained results shows that extremely long aging times considerably affect the fracture response of bonded joints under mode II (the fracture toughness of the wet-aged specimens degraded by more than $30 \%$ ). Furthermore, testing at high or cryogenic temperatures has a significant effect on the fracture response. Indeed, testing at high temperatures was observed to increase the fracture toughness (this increase ranged from $8 \%$ to $80 \%$ ) while cryogenic temperatures increased the brittleness of the adhesive which caused a substantial reduction (more than 25\%) in the fracture toughness of the bonded joint.
\end{abstract}

\section{Introduction}

The use of adhesives in the aeronautic industry has risen significantly in recent years and is now viewed as a viable alternative to traditional mechanical fasteners because adhesively bonded joints present a uniform stress distribution over the bonding area and weigh less; two features especially important for lightweight structures [1]. In the aircraft industry, bonded joints withstand extreme environmental conditions such as high and low temperatures and high levels of humidity. Because the properties of adhesives can be affected by exposure to extreme temperatures and/or moisture [2-7] and the mechanical properties of the adhesive interface can change due to being exposed to different environmental conditions [8] for long or short periods of time, these changes will affect not only the mechanical properties but also the chemical and physical properties of the interface $[9,10]$. Furthermore, temperature is used to enhance moisture absorption (i.e. hygrothermal ageing) which is one of the common methods employed to accelerate ageing in order to predict the performance of composites exposed to environmental changes [4-7]. Exposing the composites to the combination of both moisture and temperature leads to greater damage than if exposed to just moisture or temperature alone [11].

In the literature, there are different data reduction methods [12-18] with which to measure the fracture toughness of a bonded joint, most of them are based on Linear Elastic Fracture Mechanics (LEFM) while some others account for the non-linear behaviour of the joint. Based on LEFM, various test methodologies to obtain the fracture toughness in mode II were developed and standardised such as the ASTM D7905/D7905M-14 [19] for End-Notched-Flexure (ENF) test and the ISO 15114:2014 [20] for End-Loaded Split (ELS) test. Most of these methods depend on visual monitoring of the crack length, which makes them highly subjective and operator dependant [21]. Moreover, it is difficult to identify the crack front during testing at high or low temperatures in an environmental chamber. On the other hand, a mode II fracture of adhesively bonded joints usually involves the development of large fracture process zones [22]. Therefore, methods based on LEFM may not be the best option to describe the crack growth [23]. One of the pioneering methods to

\footnotetext{
* Corresponding author at: AMADE, Polytechnic School, University of Girona, Campus Montilivi s/n, 17003 Girona, Spain.

E-mail addresses: saabdelmonsef@eng.zu.edu.eg (S. Abdel-Monsef), jordi.renart@udg.edu (J. Renart), lcb@mp.aau.dk (L. Carreras), albert.turon@udg.edu (A. Turon), pere.maimi@udg.edu (P. Maimí).

1 Serra Húnter fellow, Generalitat de Catalunya, Spain.
} 
account for the influence of the FPZ is the J-integral approach, a pathindependent contour integral, presented by Rice [24]. The J-integral has been used as an alternative to the classical data reduction methodologies found in [25,26], to characterise mode II in ENF [27] and ELS [22] tests.

The results obtained with the different methods can differ due to the presence of friction, large deflection and the complex damage mechanism ahead of the crack tip $[21,25,26,28-30]$. In a recent comparison between the different data reduction methods [22] it was concluded that the ELS test is the most suitable test method for obtaining stable propagation.

Some studies into the effect of environmental degradation and weathering on the fracture properties of adhesively bonded joints can be found in the literature $[2,3,9,10,31-35]$. For instance, Banea and da Silva [36] tested two different adhesives at temperatures ranging from -40 to $90{ }^{\circ} \mathrm{C}$ and from -50 to $300{ }^{\circ} \mathrm{C}$, respectively. The increase in temperature decreased lap shear strength. Ashcroft et al. [37] observed that temperature not only affects the fracture toughness value, but it also changes the failure mode of adhesive joints. The failure mode of the adhesively bonded joints tested by Ashcroft et al. [37] changed from brittle failure at low temperatures to ductile failure at high temperatures.

Moreover, in a wet environment temperature plays a vital role in the degradation of the composites' material properties [38]. Exposure to high temperatures and the presence of moisture content decreases the fracture
Table 1

Specimen configurations tested.

\begin{tabular}{cccc}
\hline ID & Adhesive material & Test temperature & Conditioning before test \\
\hline $\mathrm{A} 1 / \mathrm{RT} / \mathrm{L}^{1}$ & $\mathrm{~A} 1$ & $\mathrm{RT}$ & No-ageing \\
$\mathrm{A} 1 /-55 / \mathrm{L}$ & & $-55^{\circ} \mathrm{C}$ & \\
\cline { 2 - 4 } $\mathrm{A} 1 /-55 / \mathrm{W}^{2}$ & $\mathrm{~A} 1$ & $-55^{\circ} \mathrm{C}$ & Wet-ageing \\
$\mathrm{A} 1 / \mathrm{RT} / \mathrm{W}$ & & $\mathrm{RT}$ & \\
$\mathrm{A} 1 / 80 / \mathrm{W}$ & & $80^{\circ} \mathrm{C}$ & No-ageing \\
\cline { 3 - 4 } $\mathrm{A} 2 / \mathrm{RT} / \mathrm{L}$ & & $\mathrm{RT}$ & \\
$\mathrm{A} 2 /-55 / \mathrm{L}$ & $\mathrm{A} 2$ & $-55^{\circ} \mathrm{C}$ & Wet-ageing \\
\cline { 2 - 4 } $\mathrm{A} 2 /-55 / \mathrm{W}$ & & $-55^{\circ} \mathrm{C}$ & \\
$\mathrm{A} 2 / \mathrm{RT} / \mathrm{W}$ & $\mathrm{A} 2$ & $\mathrm{RT}$ & \\
$\mathrm{A} 2 / 80 / \mathrm{W}$ & & $80^{\circ} \mathrm{C}$ & \\
\hline
\end{tabular}

${ }^{1}$ The specimens were stored in laboratory conditions at room temperature for four years.

${ }^{2}$ The specimens were aged in a conditioning chamber in which they were exposed to a temperature of $70{ }^{\circ} \mathrm{C}$ and a relative humidity of $85 \%$ for four years.

toughness of bonded joints tested under pure mode II [39]. Fernandes et al. [10] noticed that in specimens exposed to relative humidity between $55 \%$ and $75 \%$ while there is a slight reduction in fracture toughness, there is a significant reduction in the case of specimens immersed in water.

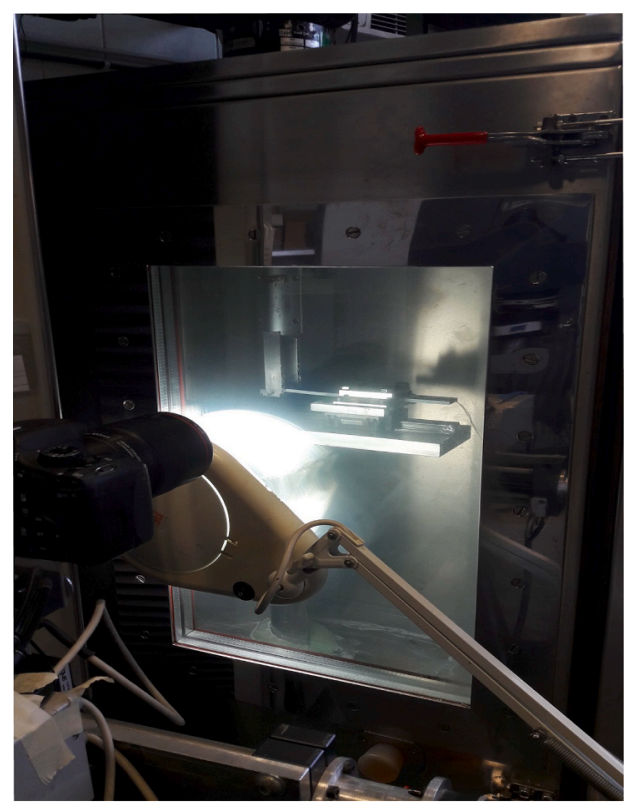

(a)

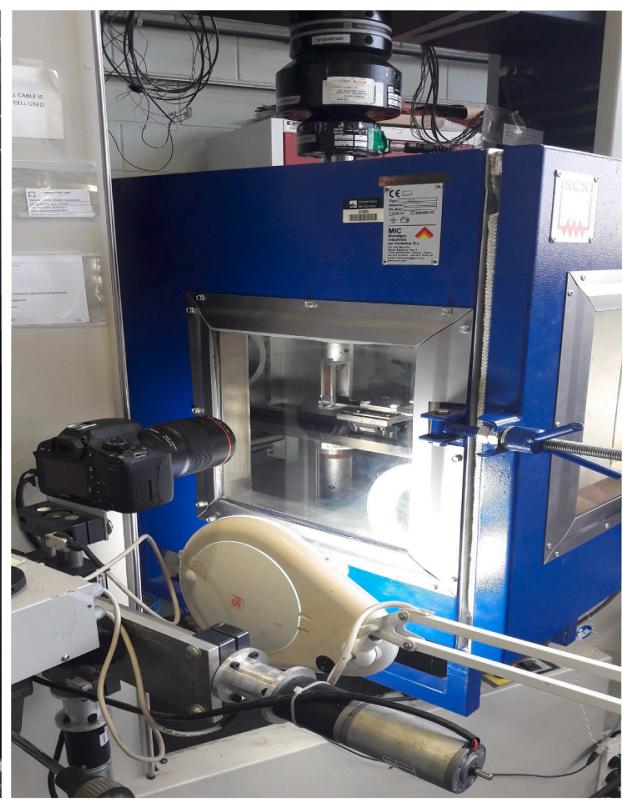

(b)

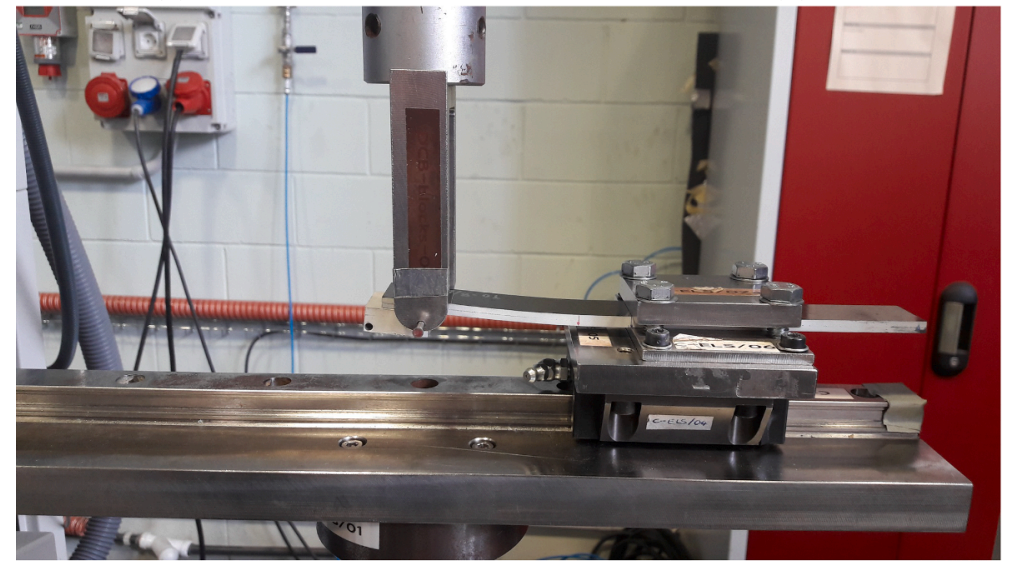

(c)

Fig. 1. Experimental setup for ELS specimens tested at: (a) $-55^{\circ} \mathrm{C}$, (b) $80^{\circ} \mathrm{C}$ and (c) room temperature (RT). 


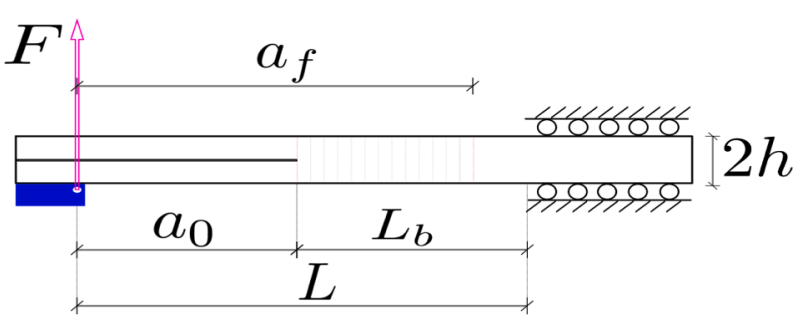

Fig. 2. Representation of the load introduction in the ELS test configuration.

LaPlante and Lee-Sullivan [35] also observed a decrease of the fracture toughness with the increase of the moisture content.

However, in the studies available it is difficult to reveal the fracture behaviour of bonded joints exposed to aggressive environmental conditions. Moreover, these studies used classical data reduction methods which require the crack length and are based on LEFM, which ignores the expected non-linearity of the adhesive layer.

In the current work, we study the effect exposure to accelerated ageing and temperature changes have on the the mode II fracture behaviour of adhesively bonded joints made with two different configurations of adhesively bonded joints (non-aged and wet-aged). The wet-aged specimens were stored in an environmental chamber (at $70{ }^{\circ} \mathrm{C}$ and $85 \% \mathrm{RH}$ ) for four years to simulate a long exposure to harsh climatic changes, while the non-aged specimens were stored (also for four years) under controlled laboratory conditions at room temperature $\left(23^{\circ} \mathrm{C} / 55 \mathrm{RH}\right)$. End Load Split (ELS) tests were performed at the same time at three different temperatures $\left(-55{ }^{\circ} \mathrm{C}\right.$, Room Temperature (RT) and $\left.80{ }^{\circ} \mathrm{C}\right)$. After testing, the obtained results were analysed, and the fracture toughness values obtained using classical methodologies were compared to the results obtained using the methodology developed by the authors $[40,41]$.

\section{Methodology}

\subsection{Material and specimen configuration}

Bonded joints were manufactured using multidirectional carbon/epoxy prepreg panels with the same stacking sequence $\left[0_{2},( \pm 45)_{2}\right]_{s}$, pre-cured in an autoclave at $180^{\circ} \mathrm{C}$ and $7 \mathrm{bar}$ for $2 \mathrm{~h}$ (dwell time). Surface preparation of the pre-cured panels was performed by abrasion followed by solvent cleaning, and after that, secondary bonded using two different epoxy adhesives films, identified as A1 and A2, which are commonly used in aircraft industry for repair purposes. The surface of the composite pre-cured panels was pre-treated using a mechanical treatment to remove the peel ply and then the bonding area was abraded using a 320-400 grade abrasive cloth and cleaning the joining area using methylethylketone (MEK). The bonded panels were cured in an autoclave at $120{ }^{\circ} \mathrm{C}$ and using only a vacuum pressure for $2 \mathrm{~h}$ (dwell time). The first adhesive film is from Cytec Engineered Materials and has a glass transition temperature $\mathrm{Tg} \approx 140^{\circ} \mathrm{C}$, while the second adhesive is from Henkel with a $\mathrm{Tg} \approx 122^{\circ} \mathrm{C}$. The adhesives were prepreg epoxy resin embedding a Mat/Polyester carrier. The test specimens were manufactured as a plate and then were cut to the final geometry of the specimens, which were then exposed to the ageing conditions. The specimens were prepared according to the ISO 15114:2014 standard [20]. The adherends and the adhesives are commonly used in the aeronautical industry. However for confidentiality reasons, their commercial names cannot be provided here. The specimens were grouped into two sets (wet-aged and non-aged) according to the ageing conditions. The wet-aged specimens were exposed to accelerated ageing (temperature of $70{ }^{\circ} \mathrm{C}$ and $85 \% \mathrm{RH}$ ) in an environmental chamber for four years to simulate long-term exposure to environmental changes. The non-aged specimens were stored in a laboratory under controlled conditions (temperature of $23 \pm 3{ }^{\circ} \mathrm{C}$ and $50 \pm 5 \%$ $\mathrm{RH}$ ) for four years to be tested at the same time as the wet-aged specimens. The bonded joint configurations are outlined in Table 1 where "*/*/W" refers to the wet-aged specimens and "*/*/L" to the non-aged specimens. The specimens were $25 \mathrm{~mm}$ wide, $210 \mathrm{~mm}$ long and with an average total thickness of $4.60 \mathrm{~mm}$. The thickness of the adhesive layer was $0.22 \pm 0.02$ $\mathrm{mm}$ in the case of the non-aged specimens and $0.3 \pm 0.015 \mathrm{~mm}$ for the wetaged specimens. A doubled layer of PTFE (Polytetrafluoroethylene) 70 long was placed at one end of the specimen to trigger the interface debonding.

\subsection{Test and instrumentation}

End Load Split (ELS) tests were performed for each material configuration in Table 1 in accordance with the procedure found in ISO

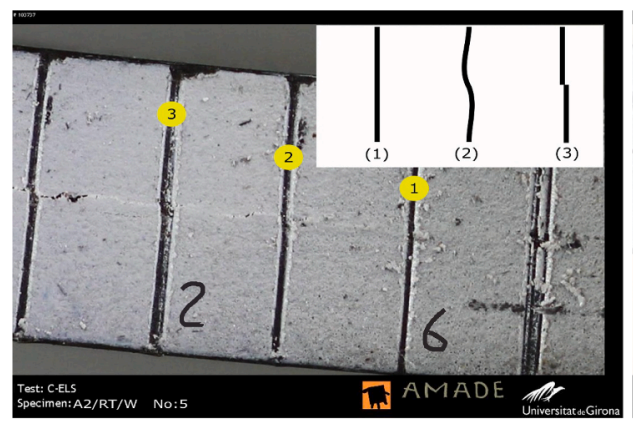

(a) RT

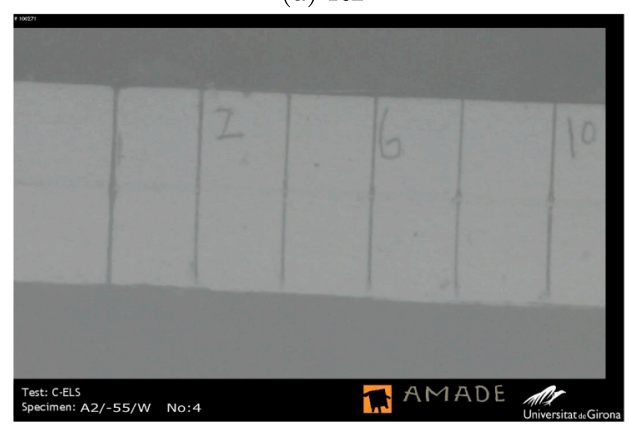

(c) $-55^{\circ} \mathrm{C}$ (without cleaning the glass)

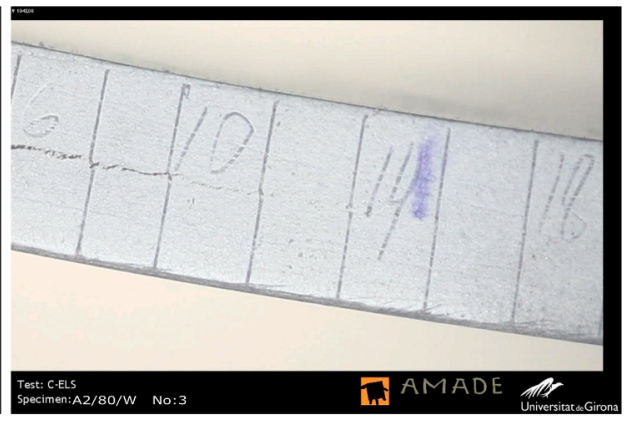

(b) $80^{\circ} \mathrm{C}$

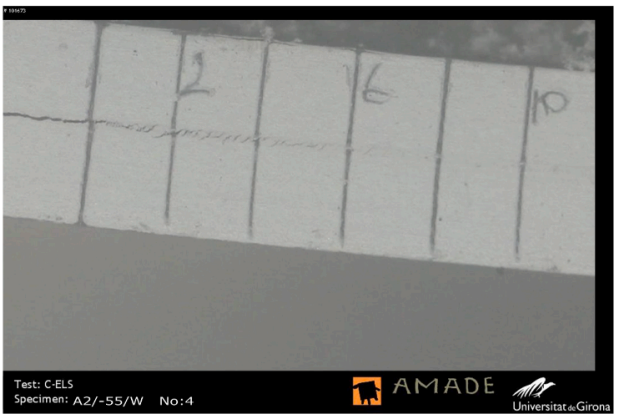

(d) $-55^{\circ} \mathrm{C}$ (having cleaned the glass)

Fig. 3. Pictures taken by the camera on side of the specimen during three different temperatures (RT, $80{ }^{\circ} \mathrm{C}$ and $-55{ }^{\circ} \mathrm{C}$ ) to monitor the crack length. 
15114:2014 [20]. The ELS test configuration was recommended by Pérez-Galmés et al. [21] to obtain stable crack propagation. The tests were carried out in an electromechanical MTS Insight test machine equipped with a $10 \mathrm{kN}$ load cell under displacement control employing a constant displacement rate $(1 \mathrm{~mm} / \mathrm{min}$ for loading and $5 \mathrm{~mm} / \mathrm{min}$ for unloading processes). All the tests were carried out at the AMADE laboratory, which is NADCAP (National Aerospace and Defense Contractors Accreditation Program) accredited for testing non-metallic materials, at the University of Girona. The wet-aged specimens were tested at three different temperatures $\left(-55{ }^{\circ} \mathrm{C}\right.$, RT and $\left.80{ }^{\circ} \mathrm{C}\right)$ according to Table 1 , while the non-aged specimens were tested at $-55^{\circ} \mathrm{C}$ and RT. Before testing, the wet specimens were removed from the environmental chamber to another temperature release box until the temperature of the specimens reached the surrounding temperature without losing their level of humidity, then they were immediately tested. The weight of the specimens was measured after removing them from the environmental chamber and just before the test. The difference in weight was ensured to be less than the accepted tolerance of $\pm 0.01 \%$. Fig. 1 shows the test setup of the ELS specimens tested at the three different temperatures. During the test a thermocouple was attached to the upper face of the specimens tested at $-55^{\circ} \mathrm{C}$ and $80^{\circ} \mathrm{C}$ to measure the real temperature of the coupons.
Before testing, the ELS fixture was calibrated using a non-precracked specimen following the ISO 15114:2014 [20] standard. For each batch, five specimens were prepared to be tested and an additional one was used for the calibration. The compliance calibration was performed at the same temperature condition as the fracture tests with a loading rate of $1 \mathrm{~mm} / \mathrm{min}$ and an unloading rate of $10 \mathrm{~mm} / \mathrm{min}$. The specimens were clamped at different free lengths of $90 \mathrm{~mm}, 80 \mathrm{~mm}, 70$ $\mathrm{mm}, 60 \mathrm{~mm}$, and $50 \mathrm{~mm}$.

To avoid the effect of the insert on the crack initiation and the unstable crack propagation, a pre-crack was performed before testing using the ELS configuration according to the procedure found in [20] and at the same temperature as the propagation test, with $\mathrm{L}=80 \mathrm{~mm}$ and $a_{0} / \mathrm{L}$ $=0.75$ (see Fig. 2)). For the pre-crack, a minimum of $5 \mathrm{~mm}$ of propagation was ensured. We performed the mode II pre-crack using the ELS configuration instead of the mode I pre-cracking to maintain the failure mechanisms for both the pre-cracking and the test. Once the pre-crack tests had been performed, the initial crack length was set to $58 \mathrm{~mm}$ with the corresponding $\mathrm{L}$ value of $100 \mathrm{~mm}\left(a_{0} / \mathrm{L} \geqslant 0.55\right)$.

The crack length was visually monitored using a video acquisition system ( 2 pictures/s) which consisted of a Canon 550D camera with a macro lens mounted on a travelling fixture. The position of the crack length was monitored by marking the edge of the specimens with ver-

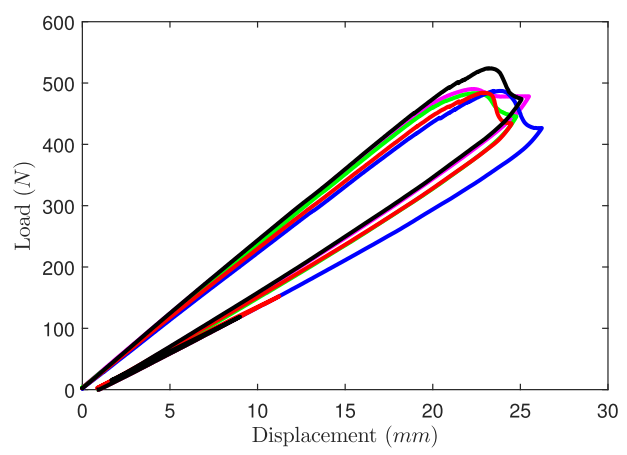

(a) $\mathrm{A} 1 / \mathrm{RT} / \mathrm{L}$

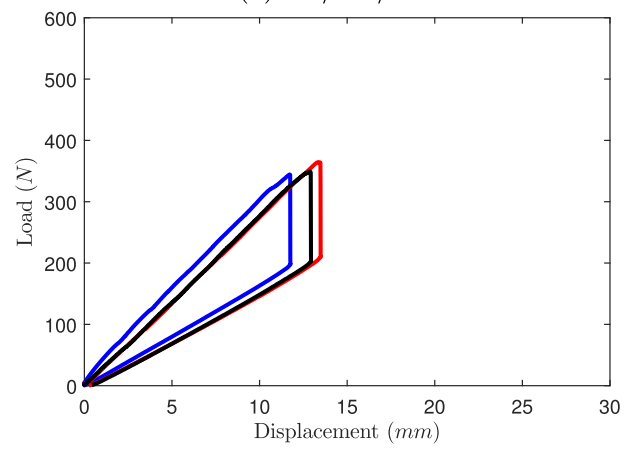

(c) $\mathrm{A} 1 /-55 / \mathrm{L}$

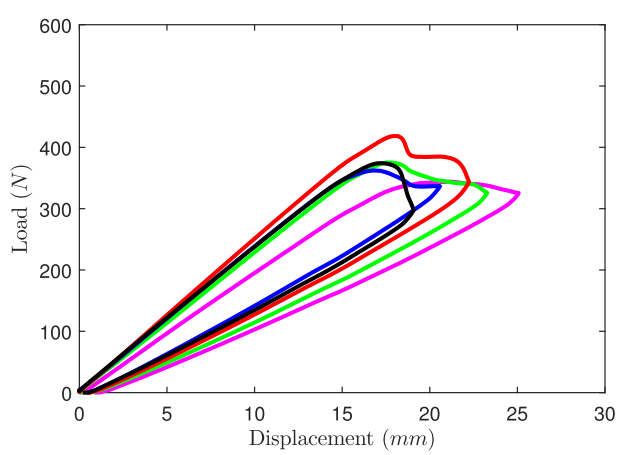

(b) $\mathrm{A} 1 / \mathrm{RT} / \mathrm{W}$

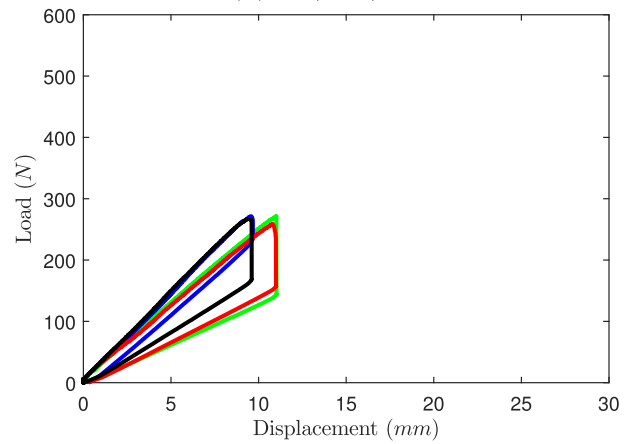

(d) $\mathrm{A} 1 /-55 / \mathrm{W}$

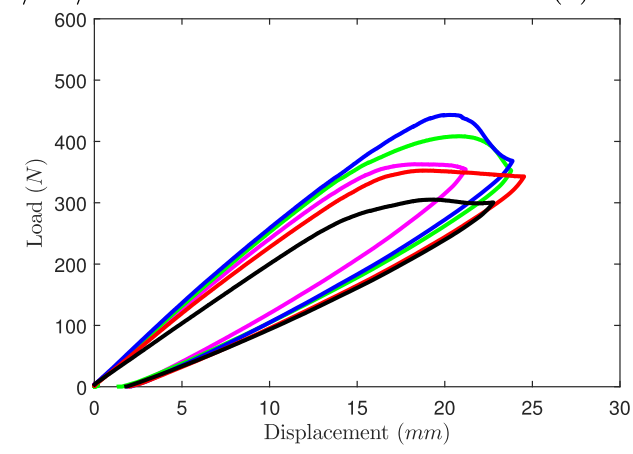

(e) $\mathrm{A} 1 / 80 / \mathrm{W}$

Fig. 4. Experimental load-displacement curves from the A1 ELS tests. 


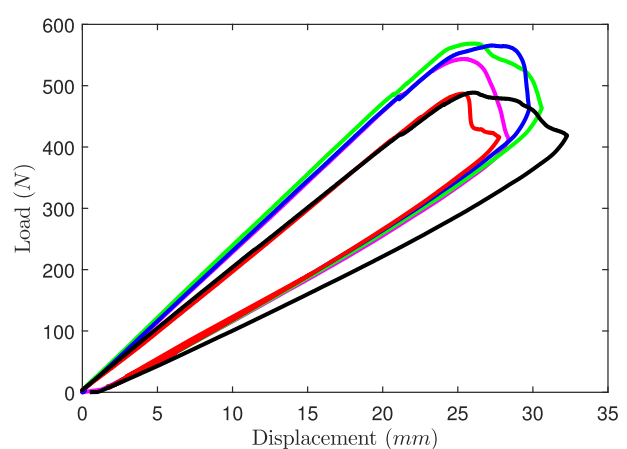

(a) A2/RT/L

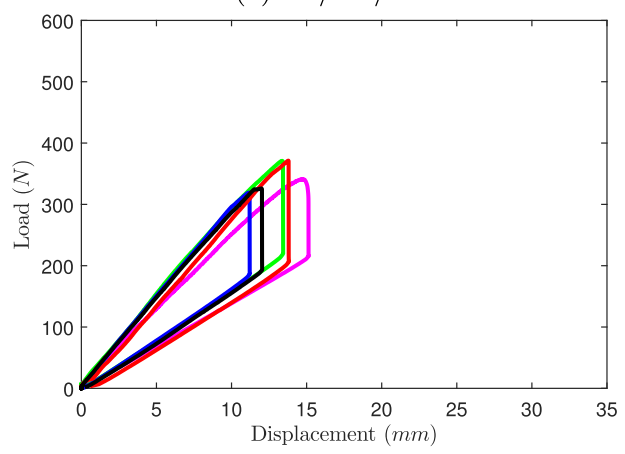

(c) $\mathrm{A} 2 /-55 / \mathrm{L}$

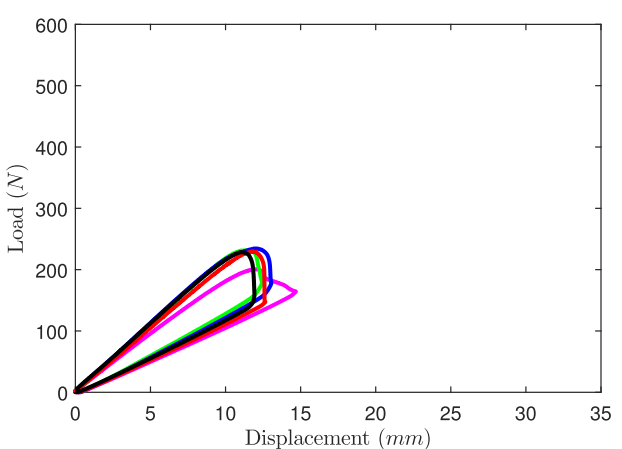

(b) $\mathrm{A} 2 / \mathrm{RT} / \mathrm{W}$

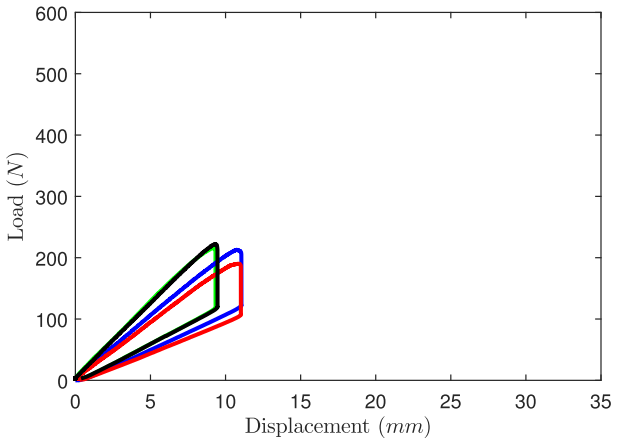

(d) $\mathrm{A} 2 /-55 / \mathrm{W}$

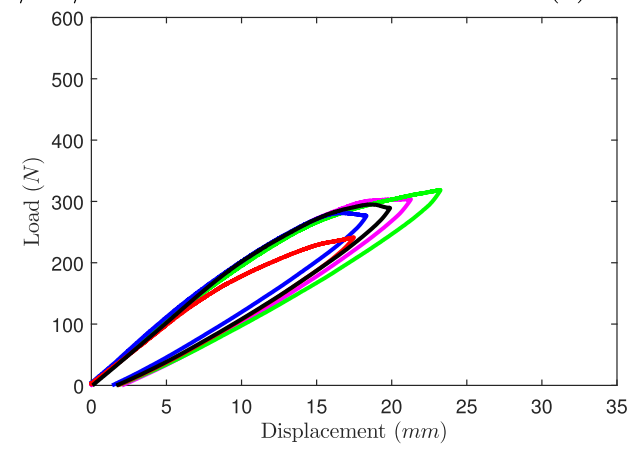

(e) $\mathrm{A} 2 / 80 / \mathrm{W}$

Fig. 5. Experimental load-displacement curves from the A2 ELS tests.

Table 2

Summary of the results of the clamp calibration test.

\begin{tabular}{ccccccc}
\hline Batch & & $\mathrm{RT} / \mathrm{L}$ & $-55 / \mathrm{L}$ & $-55 / \mathrm{W}$ & $\mathrm{RT} / \mathrm{W}$ & $80 / \mathrm{W}$ \\
\hline \multirow{2}{*}{ A1 } & $E_{1}(\mathrm{GPa})$ & 53.41 & 98.28 & 86.95 & 69.15 & 62.03 \\
& $\Delta_{\text {clamp }}(\mathrm{mm})$ & 8.83 & 22.56 & 18.91 & 11.05 & 11.02 \\
\hline \multirow{2}{*}{ A2 } & $E_{1}(\mathrm{GPa})$ & 78.85 & 121.71 & 103.31 & 70.35 & 73.2 \\
& $\Delta_{\text {clamp }}(\mathrm{mm})$ & 16.93 & 31.63 & 27.37 & 11.66 & 13.85 \\
\hline
\end{tabular}

tical lines every $2 \mathrm{~mm}$. However, it was extremely difficult to track the crack tip position during the tests, especially in the tests at $-55{ }^{\circ} \mathrm{C}$ because as the test advanced the glass misted (see Fig. 3) despite the climatic chamber glass having been cleaned before starting the tests to enhance the tracking video quality (Fig. $3 c$ and d show the difference in the quality of the picture if the glass has been cleaned or not when testing at $-55^{\circ} \mathrm{C}$ ). During the loading process, the vertical lines kinked due to the shear displacement at the crack tip, see Fig. 3a. In the current work, we determined the crack position to be where the vertical lines were broken. The outcome pictures, the load, the displacement and the specimen's temperature data were synchronised using a quantum data acquisition system. After the tests, the final crack length $\left(a_{f}\right)$ at both sides of the specimen was externally measured using an optical microscope. Finally, the specimens were opened for an optical inspection of the fractured surfaces.

\subsection{Data reduction methods}

With the aim of comparing the obtained test results, different data reduction methods were used to calculate the fracture energy values for each tested specimen. Two of the methods found in the ISO 15114:2014 [20] standard were used: the Corrected Beam Theory using Effective crack length (CBTE) and Experimental Compliance Method (ECM). In addition, an inverse methodology (INV) proposed by Abdel Monsef et al. [40], which does not require the measurement of the crack front position in the analysis, was used to obtain the fracture energy.

In the case of the Experimental Compliance Method, fracture toughness was determined during crack propagation using the following equation [20]:

$\mathscr{G}_{I I c}=\frac{3 P^{2} a^{2} m f}{2 b} ; C=C_{0}+m a^{3}$

where $b$ is the specimen width, $P$ is the applied load and $a$ is the crack length. $C_{0}$ and $m$ are constant and are obtained based upon the cubic 


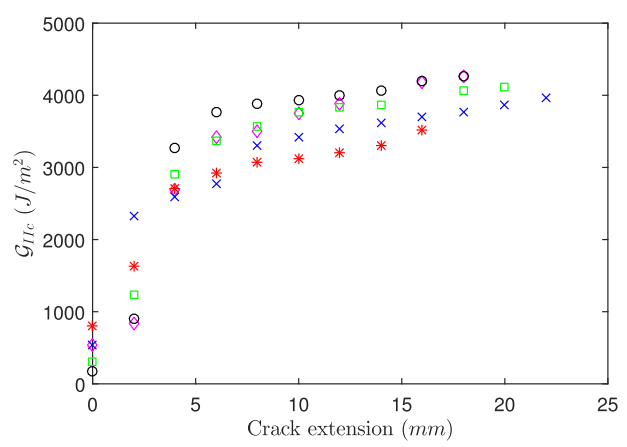

(a) $\mathrm{A} 1 / \mathrm{RT} / \mathrm{L}$

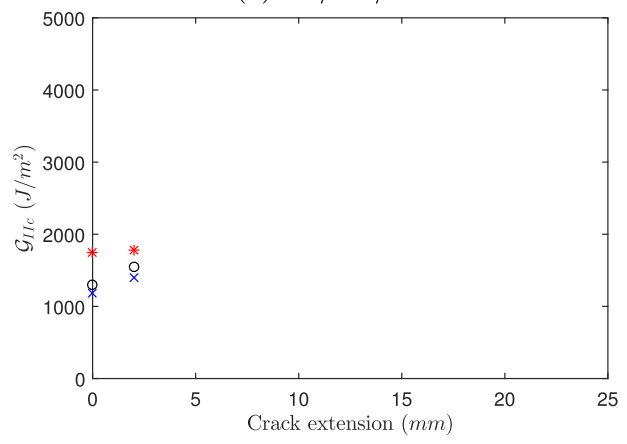

(c) $\mathrm{A} 1 /-55 / \mathrm{L}$

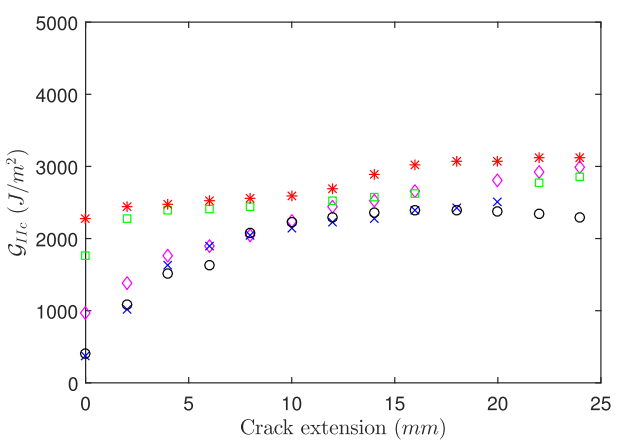

(b) $\mathrm{A} 1 / \mathrm{RT} / \mathrm{W}$

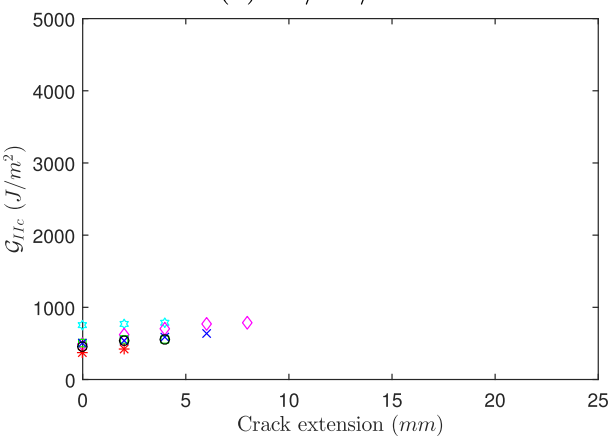

(d) $\mathrm{A} 1 /-55 / \mathrm{W}$

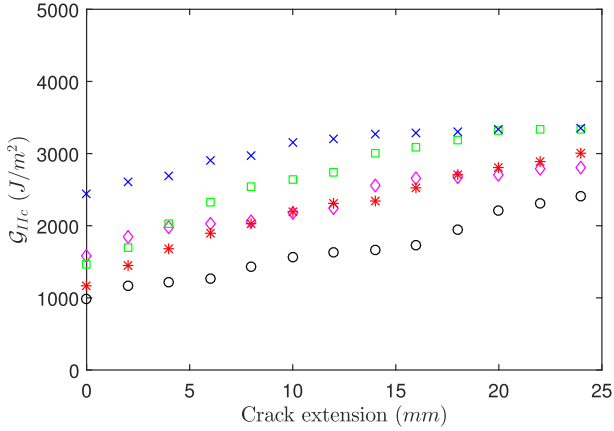

(e) $\mathrm{A} 1 / 80 / \mathrm{W}$

Fig. 6. R-Curve results from the A1 ELS tests.

relationship between the compliance $C$ and $a$ [20]. $f$ is a correction factor for large displacements.

According to the CBTE, the fracture energy is obtained with the following equation [20]:

$$
\mathscr{G}_{\text {IIc }}=\frac{9 P^{2} a_{e}^{2} f}{4 b^{2} h^{3} E_{1}} ; a_{e}=\left(\frac{1}{3}\left(2 b \frac{C}{N} h^{3} E_{1}-\left(L-\Delta_{\text {clamp }}\right)^{3}\right)\right)^{1 / 3}
$$

where $a_{e}$ is the effective crack length, $h$ is the half thickness of the specimen, $E_{1}$ is the flexural modulus obtained from the plot of the compliance cubic root $C^{1 / 3}$ versus $L: E_{1}=1 /\left(2 b(h m)^{3}\right)$ and $m$ is the slope of the clamp calibration data as described in [20]. The clamp correction $\Delta_{\text {clamp }}$ is calculated following the procedure found in [20]. $N$ and $f$ are correction factors for load-block effects and large displacements [20], respectively.

Finally, the fracture toughness can also be obtained using the inverse method proposed by Abdel Monsef et al. [40,41]. The method is an analytical procedure that involves an iterative numerical process which requires the stress intensity factors, shear displacements at the crack tip and load-point vertical displacements due to unitary loads. More details about the method and the developing procedure can be found in Abdel Monsef et al. $[40,41]$. We used this method to obtain the traction stresses and the crack shear displacements from the data from the load-displacement curve. The energy release rate $\mathscr{G}_{I I}$ is computed as:

$$
\mathscr{G}_{I I}=\int \tau d \Delta_{s}
$$

where $\tau$ are the traction stresses near the crack tip and $\Delta_{s}$ is the crack shear displacement.

\section{Results}

The results from the ELS tests performed are presented in this section. We tested 5 specimens for each ELS test type listed in Table 1.

The load-displacement curves of the wet-aged and non-aged specimens tested at different temperatures $\left(-55^{\circ} \mathrm{C}\right.$, RT and $\left.80^{\circ} \mathrm{C}\right)$ are shown in Figs. 4 and 5 for A1 and A2 specimens, respectively. The influence of the testing temperature is investigated for both the results of the nonaged and wet-aged specimens. Independent of the ageing process, the outcome response shows a slight effect on the peak load values. Furthermore, different propagation behaviour has been obtained between the specimens, where unstable crack propagation is observed in the case of specimens tested at $-55{ }^{\circ} \mathrm{C}$ while a ductile behaviour is obtained for the ones tested at $80{ }^{\circ} \mathrm{C}$. Four load-displacement curves, two specimens of $\mathrm{A} 1 /-55 / \mathrm{L}$, one of $\mathrm{A} 1 /-55 / \mathrm{W}$ and one of $\mathrm{A} 2 /-55 / \mathrm{W}$, 
have been removed from the figures due to a data acquisition system failure (in the case of $\mathrm{A} 2 /-55 / \mathrm{W}$ ) and the formation of ice on the upper face of the specimens having no crack propagation. The comparison between the results of non-aged specimens (Figs. $4 a$ and $5 a$ ) and and the accelerated aged specimens (Figa. 4b and 5b) shows that the peak load of wet-aged specimens of the configurations A1 and A2 have a reduction of $20 \%$ and $50 \%$, respectively, compared with the non-aged specimens of each configuration. The differences measured between the initial stiffness of the load-displacement curves of specimens from the same batch is due to the manual procedure followed to position the specimens or bonding the load blocks to initiate the crack length $a_{0}$, thus having different initial crack lengths.

Table 2 summarizes the average values of the flexural modulus and the clamp correction factor obtained from the clamp calibration test for adhesives A1 and A2. The columns indicate the testing conditions (temperature and ageing) and the rows the adhesives: A1 and A2.

Figs. 6 and 7 show the energy release rate $\mathscr{G}_{I I}$ calculated by means of the CBTE data reduction method vs. the crack length extension (i.e. Rcurve) for A1 and A2 specimens, respectively. For each curve, the fracture toughness was defined when the average propagation energy release rate reached a plateau. The obtained R-curves postulate the effect of temperature and ageing on the bonded joints behaviour. Shorter crack extension and a brittle behaviour were noticed in the case of specimens tested at $-55{ }^{\circ} \mathrm{C}$, while for $80{ }^{\circ} \mathrm{C}$ tests ductile behaviour happened where long crack extension associated with a small plateau was obtained, see Figs. 6e and 7e.

Besides, the inverse method developed by the authors [40] has been used to represent the J-integral vs the crack shear displacement obtained from the load-displacement curves for both specimen types: A1 (Fig. 8) and and A2 (Fig. 9). The fracture toughness was calculated when the Jintegral values reached a plateau. The maximum value of J-integral was used for the $80^{\circ} \mathrm{C}$ tests because a plateau value was not reached.

Tables 3 and 4 summarize the obtained average values of fracture toughness calculated by the data reduction methods described in the methodology section (CBTE, ECM, INV) and the coefficient of variation for A1 and A2 specimens. Tables 3 and 4 provide information for A1 specimens and $\mathrm{A} 2$ specimens, respectively, where the column indicates the specimen types listed in Table 1 and the rows indicate the data reduction method described in Section 2.3.

Fig. 10 graphically presents the differences among the data reduction methods used for both specimen types: A1 and A2. The results and the standard deviation values are normalized with respect to the results for each adhesive (A1 and A2) at room temperature and the non-aged specimens using the CBTE method. Figs. 11 and 12 show the fractured surfaces of the specimens after the tests, where we can observe a noticeable difference between the fractured surface photos
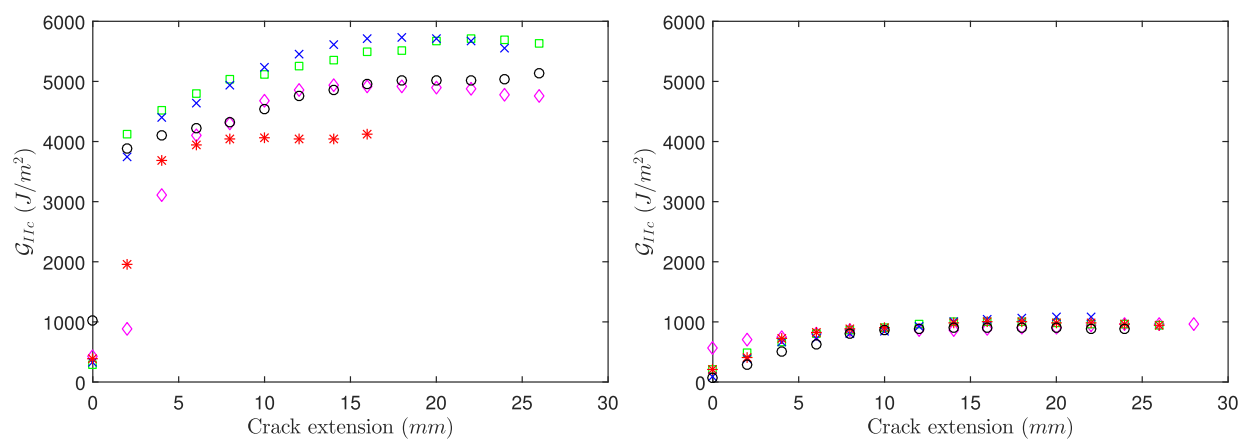

(a) $\mathrm{A} 2 / \mathrm{RT} / \mathrm{L}$

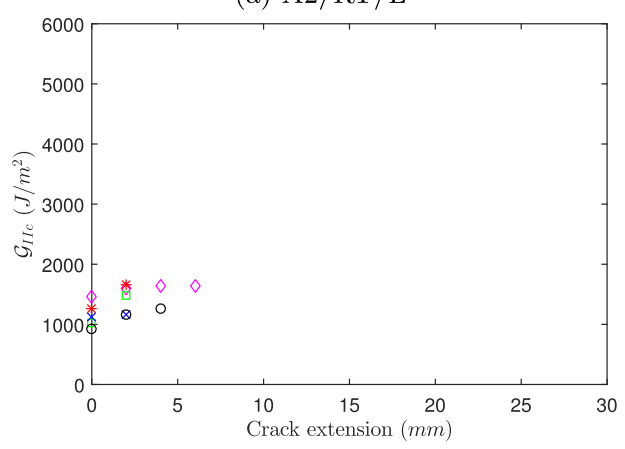

(b) $\mathrm{A} 2 / \mathrm{RT} / \mathrm{W}$

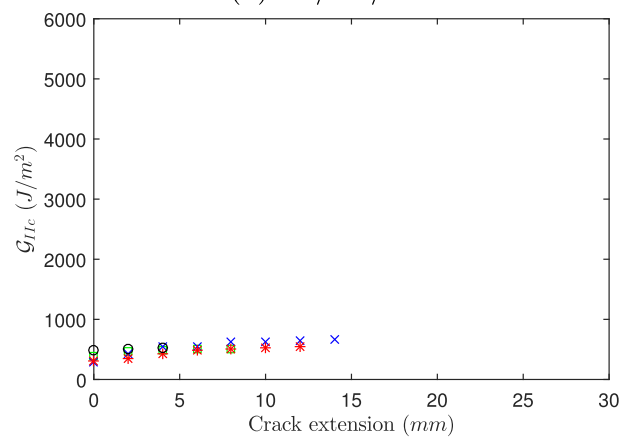

(c) $\mathrm{A} 2 /-55 / \mathrm{L}$

(d) $\mathrm{A} 2 /-55 / \mathrm{W}$

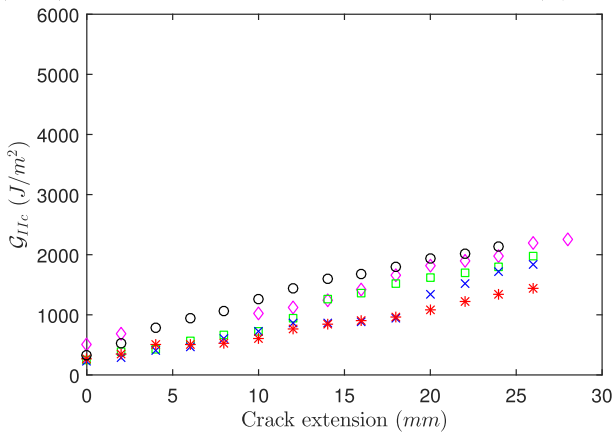

(e) $\mathrm{A} 2 / 80 / \mathrm{W}$

Fig. 7. R-Curve results from the A2 ELS tests. 


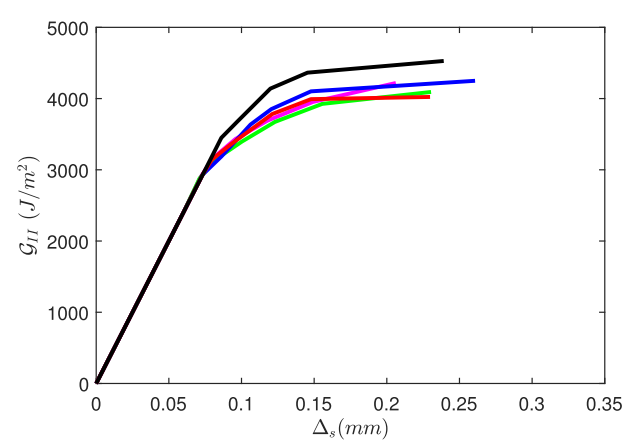

(a) $\mathrm{A} 1 / \mathrm{RT} / \mathrm{L}$

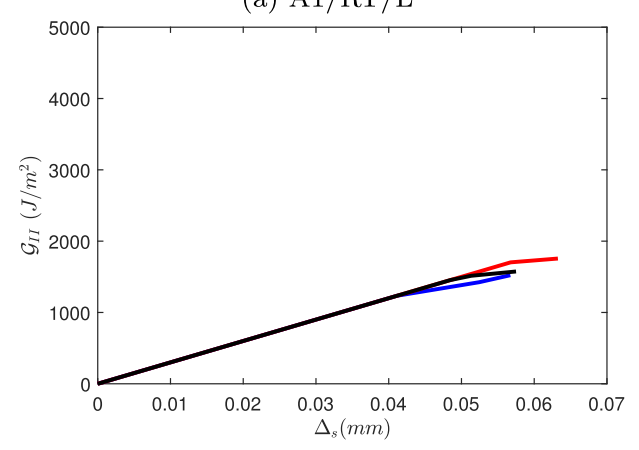

(c) $\mathrm{A} 1 /-55 / \mathrm{L}$

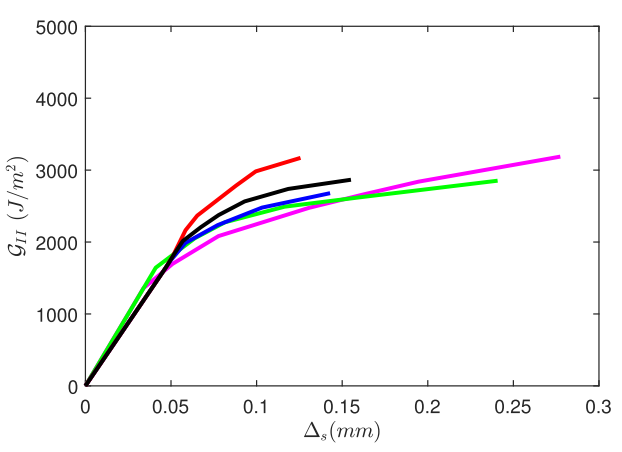

(b) $\mathrm{A} 1 / \mathrm{RT} / \mathrm{W}$

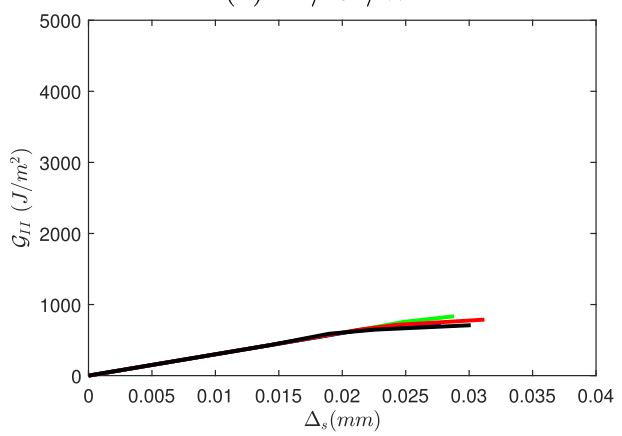

(d) $\mathrm{A} 1 /-55 / \mathrm{W}$

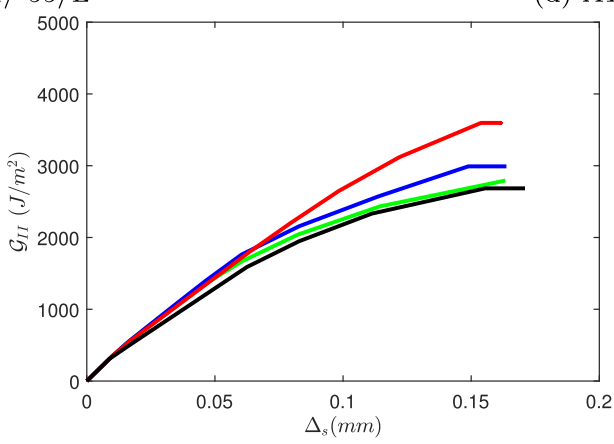

(e) $\mathrm{A} 1 / 80 / \mathrm{W}$

Fig. 8. J-integral vs the crack shear displacement at the initial crack length of the A1 ELS results.

of the representative specimens of the $\mathrm{A} 1$ and $\mathrm{A} 2$ configurations, respectively.

\section{Discussion}

The discussion concerning the obtained results is threefold: the analysis of the effect of i) temperature and, ii) ageing on the results and iii) the introduction of the inverse method as an alternative to the existing data reduction methods that require measuring or estimating the crack length.

The analysis of the load-displacement curves with the associated Rcurves and J-integral curves show that exposure to high temperatures increase the ductility of the bonded joints, as shown in Figs. 4e and 5e, for both the A1 and A2 material systems, respectively. Unlike mode I [42], the high temperature has a significant influence on the fracture toughness value of the bonded joints under mode II which increased slightly in the case of wet-aged A1 specimens (8\%) but increased by $90 \%$ in the case of the A2 specimens. For clarity, in the case of the 80 ${ }^{\circ} \mathrm{C}$ tests, neither the inverse method, nor the other classical methods capture the plateau value because as the temperature increases, the ductility of the adhesive increases, resulting in an additional plastic deformation [43] where the final crack length $a_{0}$ reached $90 \%$ of the free length $L$. Therefore, some of the R-curves or the J-integral curves do not reach a plateau value, while a short plateau was noticed for the rest. On the other hand, cryogenic temperatures cause a significant change in the propagation behaviour where a very short crack extension was obtained, see Figs. $4 \mathrm{~d}$ and $5 \mathrm{~d}$. This is because the adhesive becomes brittle at low temperatures $[44,45]$. Moreover, testing at a low temperature significantly affects the fracture toughness, which decreased in the case of non-aged A1 specimens by $63 \%$ of the room temperature value and $75 \%$ in the case of non-aged A2 specimens. The same behaviour occurred in the case of wet-aged specimens where the fracture toughness of the specimens tested at $-55^{\circ} \mathrm{C}$ degraded by $77 \%$ and $50 \%$ of the RT specimens for A1 and A2 configurations, respectively. The specimens' failure mechanism tested at $-55{ }^{\circ} \mathrm{C}$ is an adhesive failure, as shown in Figs. 11 and 12, where there is no crack growing inside the adhesive layer. The measured fracture energy at $-55^{\circ} \mathrm{C}$ is driven by the adhesive interface failure, which is expected to be lower than the cohesive failure. Therefore, there is no fracture toughness of the adhesive material measured.

Regarding the wet ageing effect, a significant reduction in the fracture toughness values was obtained from the comparison of wet-aged and non-aged specimens, as shown in Figs. 6 and 7 in the case of both A1 ad A2 specimen types, respectively, where $\mathscr{S}_{\text {IIc }}(A 1 / R T / W)$ is $70 \%$ of $\mathscr{G}_{\text {IIc }}(A 1 / R T / L)$ on $\mathrm{A} 1$ and $\left(\mathscr{G}_{\text {IIc }}(A 2 / R T / L)\right.$ is $20 \%$ of $\mathscr{G}_{\text {IIc }}(A 2 / R T / W)$ on A2. The ageing process has a significant effect on the behaviour of the 


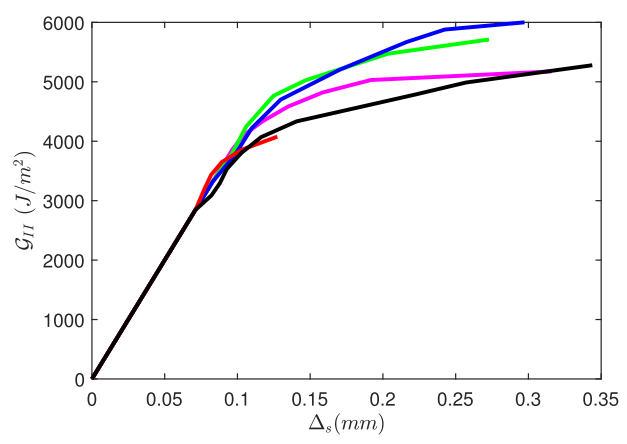

(a) $\mathrm{A} 2 / \mathrm{RT} / \mathrm{L}$

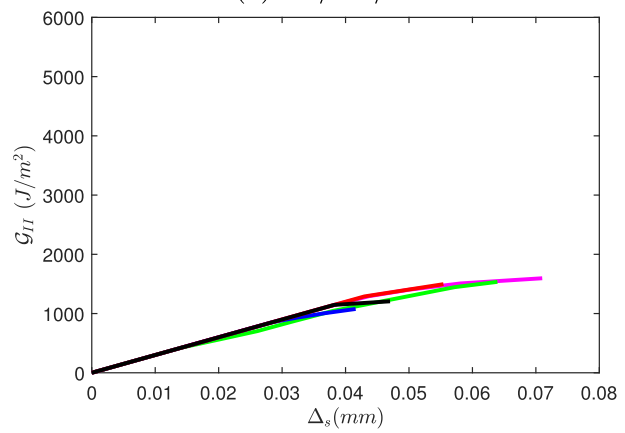

(c) $\mathrm{A} 2 /-55 / \mathrm{L}$

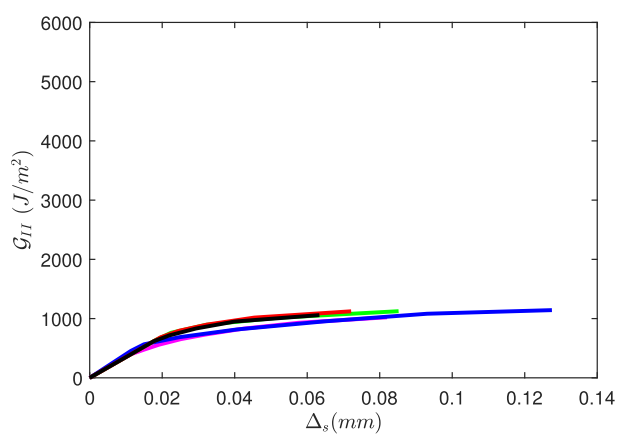

(b) $\mathrm{A} 2 / \mathrm{RT} / \mathrm{W}$

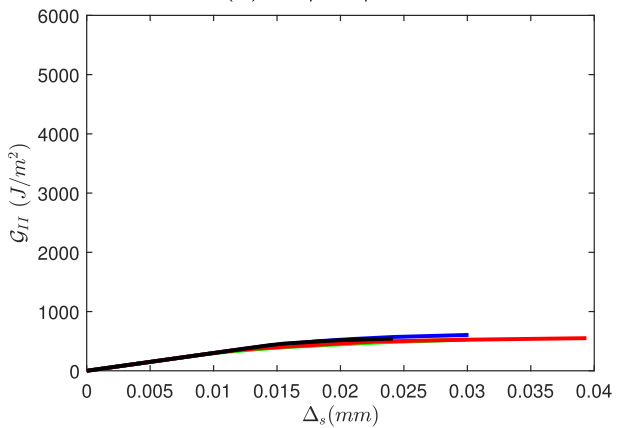

(d) $\mathrm{A} 2 /-55 / \mathrm{W}$

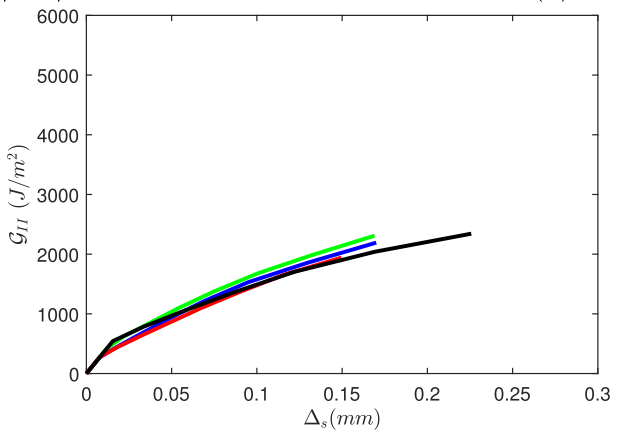

(e) $\mathrm{A} 2 / 80 / \mathrm{W}$

Fig. 9. J-integral vs the crack shear displacement at the initial crack length of the A2 ELS results.

Table 3

Summary of A1 ELS test results.

\begin{tabular}{ccccccc}
\hline & & $\begin{array}{c}\mathrm{A} 1 / \\
\mathrm{RT} / \mathrm{L}\end{array}$ & $\begin{array}{c}\mathrm{A} 1 /- \\
55 / \mathrm{L}\end{array}$ & $\begin{array}{c}\mathrm{A} 1 /- \\
55 / \mathrm{W}\end{array}$ & $\begin{array}{c}\mathrm{A} 1 / \\
\mathrm{RT} / \mathrm{W}\end{array}$ & $\begin{array}{c}\mathrm{A} 1 / 80 / \\
\mathrm{W}\end{array}$ \\
\hline \multirow{2}{*}{$G_{\text {IIC }}(\mathrm{ECM})$} & $\begin{array}{c}\text { Average } \\
\left(\mathrm{J} / \mathrm{m}^{2}\right)\end{array}$ & 3872 & - & - & 2500 & 2702 \\
& $\mathrm{CV}^{1}(\%)$ & 6.34 & - & - & 6.43 & 18.21 \\
\hline \multirow{2}{*}{$G_{\text {IIc }}(\mathrm{CBTE})$} & $\begin{array}{c}\text { Average } \\
\left(\mathrm{J} / \mathrm{m}^{2}\right)\end{array}$ & 4033 & 1492 & 645 & 2823 & 3025 \\
& $\begin{array}{c}\mathrm{CV}(\%) \\
G_{\text {IIc }}(\mathrm{INV})^{2}\end{array}$ & 7.66 & 16.50 & 17.28 & 12.38 & 13.77 \\
& $\begin{array}{c}\text { Average } \\
\left(\mathrm{J} / \mathrm{m}^{2}\right)\end{array}$ & 4235 & 1613 & 766 & 2944 & 2944 \\
& $\mathrm{CV}(\%)$ & 4.75 & 7.56 & 7.87 & 7.45 & 13.83 \\
\hline
\end{tabular}

\footnotetext{
1 Coefficient of variation
}

2 Inverse Method

material, which is in agreement with Fernandes et al. [9], although the extremely long ageing process followed (four years) is too conservative and may not be representative of actual aircraft operating conditions.

The visual inspection of the fractured surfaces shows a significant effect of temperature not only on the failure mode, but also on the colour
Table 4

Summary of A2 ELS test results.

\begin{tabular}{ccccccc}
\hline & & $\mathrm{A} 2 /$ & $\mathrm{A} 2 /-$ & $\mathrm{A} 2 /-$ & $\mathrm{A} 2 /$ & $\mathrm{A} 2 / 80 /$ \\
& $\mathrm{RT} / \mathrm{L}$ & $55 / \mathrm{L}$ & $55 / \mathrm{W}$ & $\mathrm{RT} / \mathrm{W}$ & $\mathrm{W}$ \\
\hline$G_{\text {IIC }}(\mathrm{ECM})$ & $\begin{array}{c}\text { Average } \\
\left(\mathrm{J} / \mathrm{m}^{2}\right) \\
\mathrm{CV}^{1}(\%)\end{array}$ & 4882 & 1424 & - & 814 & 1475 \\
\hline$G_{\text {IIc }}(\mathrm{CBTE})$ & $\begin{array}{c}\text { Average } \\
\left(\mathrm{J} / \mathrm{m}^{2}\right)\end{array}$ & 5085 & 1271 & 509 & 1017 & 1932 \\
& $\mathrm{CV}^{1}(\%)$ & 13.69 & 15.68 & 7.65 & 6.28 & 16.37 \\
\hline$G_{\text {IIC }}(\mathrm{INV})^{2}$ & $\begin{array}{c}\text { Average } \\
\left(\mathrm{J} / \mathrm{m}^{2}\right)\end{array}$ & 5187 & 1373 & 559 & 1068 & 2034 \\
& $\mathrm{CV}(\%)$ & 13.58 & 16.39 & 6.07 & 4.72 & 15.48 \\
\hline
\end{tabular}

\footnotetext{
${ }^{1}$ Coefficient of variation

2 Inverse Method
}

of the surface. An evident change in the colour of the fractured surfaces was observed and this represents the changes in physical alteration of adhesive material. The colour of the wet-aged specimens tends to brown and dark brown in case of specimens tested at $-55^{\circ} \mathrm{C}$; in agreement with Fernandes et al. $[9,10]$. Cohesive failure was the predominant fracture 


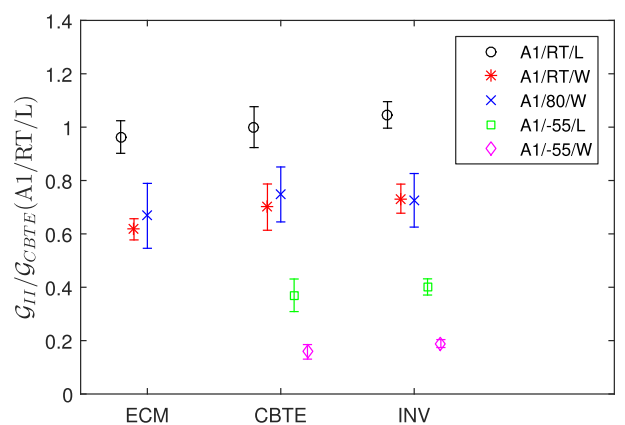

(a)

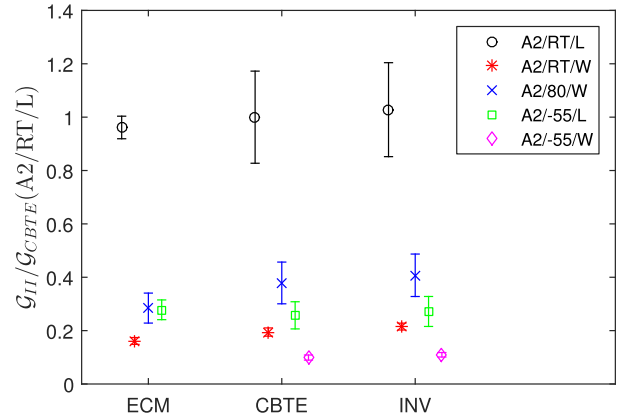

(b)

Fig. 10. Summary of the ELS results. All values are normalized with the CBTE results of the non-aged specimens tested at RT.
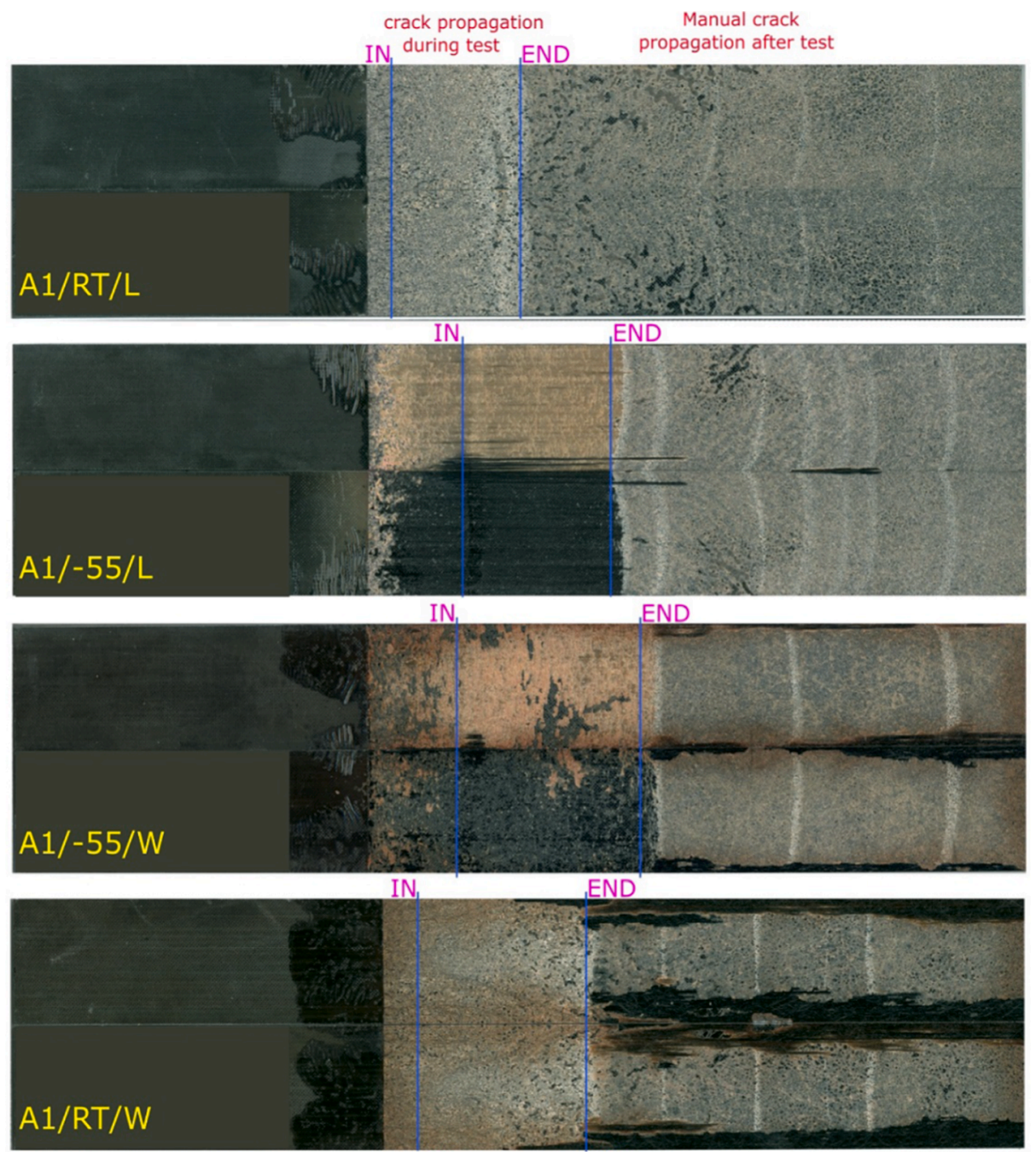

IN END

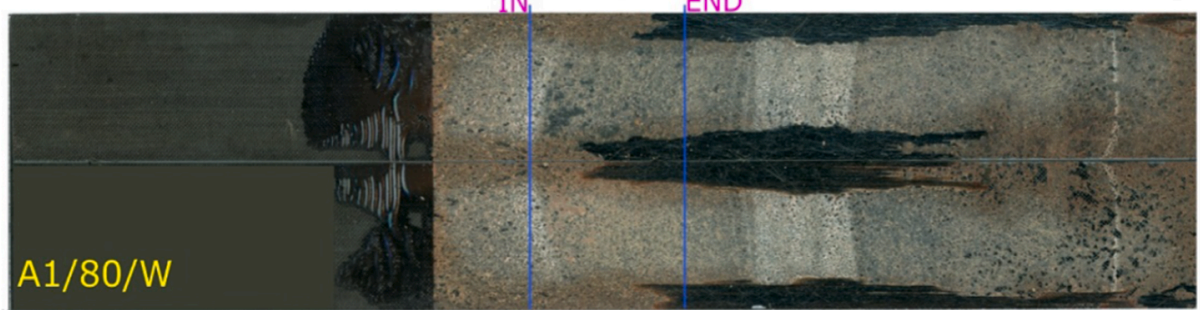

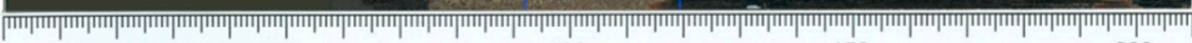
0

Fig. 11. Fractured surface pictures of the tested ELS A1 specimens. The end of the pre-crack region and the final crack propagation during the test are indicated with IN and END, respectively, for each fractured surface. 

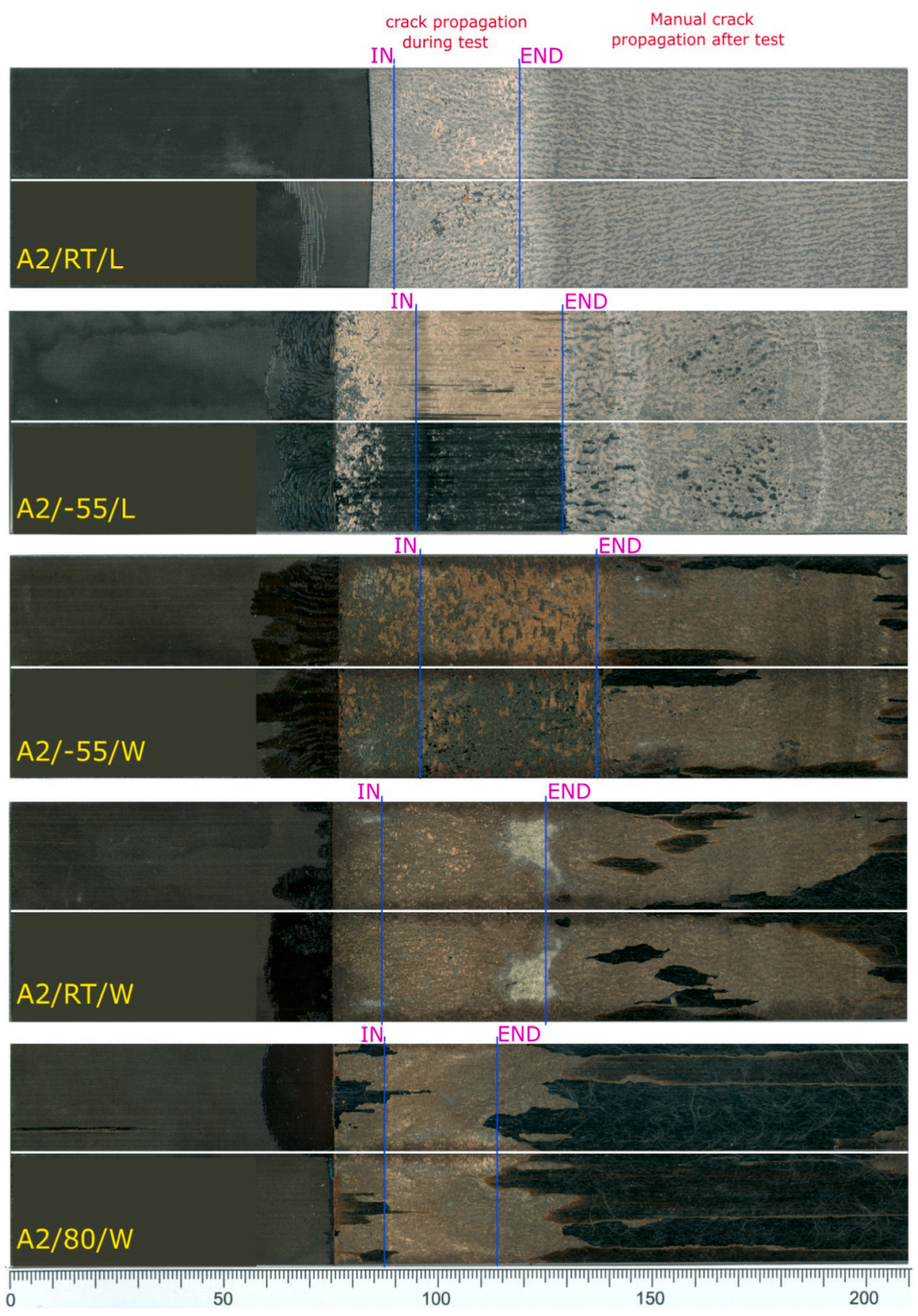

Fig. 12. Fractured surface pictures of the tested ELS A2 specimens. The end of the pre-crack region and the final crack propagation during the test are indicated with IN and END, respectively, for each fractured surface.

mode of the RT and $80^{\circ} \mathrm{C}$ tests. However, the cryogenic temperature was the main source of the change in the failure mode, from the purely cohesive mode in the specimens, tested at room temperature or $80^{\circ} \mathrm{C}$, to adhesive failure. For the wet-aged specimens tested at $-55^{\circ} \mathrm{C}$, the crack propagation path moved from the lower adhesive interface to the upper interface producing adhesive failure with some irregularities in the fractured surface while we observed a pure adhesive failure in case of the non-aged specimens. The authors suggest that the freezing temperatures increased the brittleness of the adhesive interface and decreased the adhesion between the adhesive and the adherend, which direct the crack propagation to the weakest path thus causing adhesive failure. On the other hand, the moisture content enhances the ductility of the adhesive which considers the source of differences found between the -55 ${ }^{\circ} \mathrm{C}$ tests' fracture surfaces, Figs. 11 and 12. For clarity, we consider the bonded joints' behaviour is driven by the adhesive properties where neither plastic deformation nor crack growth were observed within the adherend (no damage occurred in the adherend plies which could contribute to the overall dissipation process). Moreover, in agreement with what we observed in the mode I tests [42], both high temperature and ageing have a slight effect on the measured flexural modulus, whereas freezing temperatures have a notable effect on increasing the flexural modulus as listed in Table 2.

The inverse method developed by Abdel Monsef et al. $[40,41]$ was used to obtain the J-integral values of the specimens tested under extreme environmental conditions, where visual access to the specimens (required by standard methods) may be difficult. The R-curves have been represented against the crack extension, while the J-curves are drawn with respect to the crack shear displacements. From the J- 
curve it is possible to derive the cohesive law that is the input law of cohesive elements. The fracture toughness values, which were obtained using the inverse method developed by the authors [40] using the load-displacement curves, were compared to the results obtained by the classical data reduction techniques (CBTE and ECM). The use of each method has some limitations. The experimental compliance method requires the crack front position during the test, which is challenging to track when testing using a climatic chamber, especially in the case of $-55{ }^{\circ} \mathrm{C}$ tests as shown in Fig. 3c. In addition, this method and the CBTE require the value of the flexural modulus which requires an additional test (the three point bending test or the clamp calibration test) [20]. On the other hand, the inverse method allows us to determine the fracture properties of the bonded joint without the need to measure the crack extension. Although the inverse method considers the $2 \mathrm{D}$ plane strain problem $[40,41]$, a good agreement between the inverse method and the classical methodologies results for both campaign adhesive joints is obtained with differences being lower than $10 \%$.

\section{Conclusions}

In the current work, the influence of temperature and ageing on the mode II fracture response of two material configurations of secondary bonded joints (A1 and A2) was experimentally studied. The adhesively bonded joints (wet-aged and non-aged) were tested using the ELS test configuration at various temperatures $\left(-55^{\circ} \mathrm{C}\right.$, RT and $80^{\circ} \mathrm{C}$ ). From the analysis of the results, temperature plays a vital role in defining the fracture mode and propagation response of the bond interface, while the fracture mode was a cohesive failure for both the RT and $80^{\circ} \mathrm{C}$ tests, adhesive failure was observed in the -55 ${ }^{\circ} \mathrm{C}$ tests because of a brittle response of the adhesive layer. Moreover, the high-temperature testing increases the fracture process zone length. The ageing process has a significant influence on the adhesive joint fracture response where the fracture toughness of the wetaged specimens significantly degraded, especially in the case of the A2 material system where the curing temperature is closer to the $\mathrm{Tg}$. Ageing caused reductions of $30 \%$ and $80 \%$ in the fracture toughness of the configurations A1 and A2, respectively. Finally, an inverse method was used to extract the J-integral using the experimental load-displacement curves without the need to monitor crack extension or for any additional tests (which are required by the classical methods). The results from the method were compared to other data reduction methods and showed a good agreement between them.

\section{CRediT authorship contribution statement}

S. Abdel-Monsef: Conceptualization, Methodology, Investigation, Writing - original draft. J. Renart: Supervision, Methodology, Writing review \& editing. L. Carreras: Methodology, Writing - review \& editing. A. Turon: Supervision, Methodology, Writing - review \& editing. P. Maimí: Methodology, Writing - review \& editing.

\section{Declaration of Competing Interest}

The authors declare that they have no known competing financial interests or personal relationships that could have appeared to influence the work reported in this paper.

\section{Acknowledgements}

The first author would like to acknowledge the support of the Catalan Government (Agéncia de Gestió d'Ajuts Universitaris i de Recerca), under Grant 2017 FI_B 00100. This work has been partially funded by the Spanish Government (Ministerio de Economia y Competitividad) under contracts RTI2018-099373-B-I00 and RTI2018-097880-B-I00.

\section{References}

[1] M. Banea, L.F. da Silva, Adhesively bonded joints in composite materials: an overview, Proc. Inst. Mech. Eng. Part L: J. Mater.: Des. Appl. 223 (1) (2009) 1-18.

[2] A. Crocombe, Y. Hua, W. Loh, M. Wahab, I. Ashcroft, Predicting the residual strength for environmentally degraded adhesive lap joints, Int. J. Adhes. Adhes. 26 (5) (2006) 325-336.

[3] W. Loh, A. Crocombe, M.A. Wahab, I. Ashcroft, Environmental degradation of the interfacial fracture energy in an adhesively bonded joint, Eng. Fract. Mech. 69 (18) (2002) 2113-2128.

[4] R.S. Ashofteh, H. Khoramishad, The influence of hygrothermal ageing on creep behavior of nanocomposite adhesive joints containing multi-walled carbon nanotubes and graphene oxide nanoplatelets, Int. J. Adhes. Adhes. 94 (2019) 1-12.

[5] H. Khoramishad, R. Ashofteh, H. Pourang, F. Berto, Experimental investigation of the influence of temperature on the reinforcing effect of graphene oxide nanoplatelet on nanocomposite adhesively bonded joints, Theoret. Appl. Fract. Mech. 94 (2018) 95-100.

[6] H. Khoramishad, O. Alizadeh, L. Da Silva, Effect of multi-walled carbon nanotubes and silicon carbide nanoparticles on the deleterious influence of water absorption in adhesively bonded joints, J. Adhes. Sci. Technol. 32 (16) (2018) 1795-1808.

[7] R.S. Ashofteh, H. Khoramishad, Creep behavior of polymeric adhesive joints exposed to different environmental conditions, Polym. Compos. (2020).

[8] H. Khoramishad, O. Alizadeh, Effects of silicon carbide nanoparticles and multiwalled carbon nanotubes on water uptake and resultant mechanical properties degradation of polymer nanocomposites immersed in hot water, Polym. Compos. 39 (S2) (2018) E883-E890.

[9] R. Fernandes, M. de Moura, R. Moreira, Effect of temperature on pure modes I and II fracture behavior of composite bonded joints, Compos. Part B: Eng. 96 (2016) 35-44.

[10] R. Fernandes, M. De Moura, R. Moreira, Effect of moisture on pure mode I and II fracture behaviour of composite bonded joints, Int. J. Adhes. Adhes. 68 (2016) 30-38.

[11] S. Budhe, M. Banea, S. De Barros, L. Da Silva, An updated review of adhesively bonded joints in composite materials, Int. J. Adhes. Adhes. 72 (2017) 30-42.

[12] D.R. Moore, J. Williams, A. Pavan, Fracture mechanics testing methods for polymers, adhesives and composites, vol. 28, Elsevier, 2001.

[13] Q. Yang, M. Thouless, S. Ward, Elastic-plastic mode-II fracture of adhesive joints, Int. J. Solids Struct. 38 (18) (2001) 3251-3262.

[14] L.F. da Silva, F. De Magalhães, F. Chaves, M. De Moura, Mode II fracture toughness of a brittle and a ductile adhesive as a function of the adhesive thickness, J. Adhes. 86 (9) (2010) 891-905.

[15] N. Sela, O. Ishai, L. Banks-Sills, The effect of adhesive thickness on interlaminar fracture toughness of interleaved CFRP specimens, Composites 20 (3) (1989) $257-264$.

[16] M. De Moura, R. Campilho, J. Gonçalves, Pure mode II fracture characterization of composite bonded joints, Int. J. Solids Struct. 46 (6) (2009) 1589-1595.

[17] J. Azevedo, R. Campilho, F. Da Silva, T. Faneco, R. Lopes, Cohesive law estimation of adhesive joints in mode II condition, Theoret. Appl. Fract. Mech. 80 (2015) $143-154$.

[18] I. Floros, K. Tserpes, T. Löbel, Mode-I, mode-II and mixed-mode I+ II fracture behavior of composite bonded joints: Experimental characterization and numerical simulation, Compos. Part B: Eng. 78 (2015) 459-468.

[19] D7905/D7905M-14, A. Standard test method for determination of the Mode II interlaminar fracture toughness of unidirectional fiber-reinforced polymer matrix composites. 2014.

[20] ISO 15114: 2014, Fibre-Reinforced Plastic Composites-Determination of the Mode II Fracture Resistance for Unidirectionally Reinforced Materials Using the Calibrated End-Loaded Split (C-ELS) Test and an Effective Crack Length Approach, 2014.

[21] M. Pérez-Galmés, J. Renart, C. Sarrado, A. Brunner, A. Rodríguez-Bellido, Towards a consensus on mode II adhesive fracture testing: experimental study, Theoret. Appl. Fract. Mech. 98 (2018) 210-219.

[22] M. Pérez-Galmés, J. Renart, C. Sarrado, A. Rodríguez-Bellido, J. Costa, A data reduction method based on the J-integral to obtain the interlaminar fracture toughness in a mode II end-loaded split (ELS) test, Compos. Part A: Appl. Sci. Manuf. 90 (2016) 670-677.

[23] C. Sarrado, A. Turon, J. Costa, J. Renart, On the validity of linear elastic fracture mechanics methods to measure the fracture toughness of adhesive joints, Int. J. Solids Struct. 81 (2016) 110-116.

[24] J.R. Rice, A path independent integral and the approximate analysis of strain concentration by notches and cracks, J. Appl. Mech. 35 (2) (1968) 379-386.

[25] P. Davies, B. Blackman, A. Brunner, Standard test methods for delamination resistance of composite materials: current status, Appl. Compos. Mater. 5 (6) (1998) 345-364.

[26] P. Davies, G. Sims, B. Blackman, A. Brunner, K. Kageyama, M. Hojo, et al., Comparison of test configurations for determination of mode II interlaminar fracture toughness results from international collaborative test programme, Plast. Rubber Compos. 28 (9) (1999) 432-437.

[27] U. Stigh, K.S. Alfredsson, A. Biel, Measurement of cohesive laws and related problems, in: ASME 2009 international mechanical engineering congress and exposition, American Society of Mechanical Engineers, 2009, pp. 293-298.

[28] P. Davies, H. Kausch, J. Williams, A. Kinloch, M. Charalambides, A. Pavan, et al., Round-robin interlaminar fracture testing of carbon-fibre-reinforced epoxy and PEEK composites, Compos. Sci. Technol, 43 (2) (1992) 129-136.

[29] B.D. Davidson, X. Sun, A.J. Vinciquerra, Influences of friction, geometric nonlinearities, and fixture compliance on experimentally observed toughnesses 
from three and four-point bend end-notched flexure tests, J. Compos. Mater. 41 (10) (2007) 1177-1196.

[30] B.D. Davidson, X. Sun, Effects of friction, geometry, and fixture compliance on the perceived toughness from three-and four-point bend end-notched flexure tests, J. Reinforced Plast. Compos. 24 (15) (2005) 1611-1628.

[31] J.M. Arenas, R. Ocaña, C. Alía, J.J. Narbón, M. Islán, Fracture energy in structural adhesive joints of composite-aluminum under adverse environments conditions, J. Adhes. Sci. Technol. 28 (2) (2014) 201-214.

[32] M. Banea, L. Da Silva, R. Campilho, Mode I fracture toughness of adhesively bonded joints as a function of temperature: experimental and numerical study, Int. J. Adhes. Adhes. 31 (5) (2011) 273-279.

[33] G. Charalambous, G. Allegri, S.R. Hallett, Temperature effects on mixed mode I/II delamination under quasi-static and fatigue loading of a carbon/epoxy composite, Compos. Part A: Appl. Sci. Manuf. 77 (2015) 75-86.

[34] K. Katnam, J. Sargent, A. Crocombe, H. Khoramishad, I. Ashcroft, Characterisation of moisture-dependent cohesive zone properties for adhesively bonded joints, Eng. Fract. Mech. 77 (16) (2010) 3105-3119.

[35] G. LaPlante, P. Lee-Sullivan, Moisture effects on FM300 structural film adhesive: Stress relaxation, fracture toughness, and dynamic mechanical analysis, J. Appl. Polym. Sci. 95 (5) (2005) 1285-1294.

[36] M.D. Banea, L.F. da Silva, Mechanical characterization of flexible adhesives, J. Adhes. 85 (4-5) (2009) 261-285.

[37] I. Ashcroft, D. Hughes, S. Shaw, Mode I fracture of epoxy bonded composite joints: 1. Quasi-static loading, Int. J. Adhes. Adhes. 21 (2) (2001) 87-99.
[38] B. Ray, Temperature effect during humid ageing on interfaces of glass and carbon fibers reinforced epoxy composites, J. Colloid Interface Sci. 298 (1) (2006) $111-117$.

[39] L. Asp, The effects of moisture and temperature on the interlaminar delamination toughness of a carbon/epoxy composite, Compos. Sci. Technol. 58 (6) (1998) 967-977.

[40] S. Abdel Monsef, M. Pérez-Galmés, J. Renart, A. Turon, P. Maimí, The influence of mode II test configuration on the cohesive law of bonded joints, Compos. Struct. 234 (2020) 111689.

[41] S. Abdel Monsef, A. Ortega, A. Turon, P. Maimí, J. Renart, An efficient method to extract a mode I cohesive law for bonded joints using the double cantilever beam test, Compos. Part B: Eng. 178 (2019) 107424.

[42] S. Abdel-Monsef, J. Renart, L. Carreras, P. Maimí, A. Turon, Effect of environmental conditioning on pure mode i fracture behaviour of adhesively bonded joints, Theoret. Appl. Fract. Mech. (2020) 102826.

[43] J. Moller, R. Hunter, J. Molina, A. Vizán, J. Peréz, L. da Silva, Influence of the temperature on the fracture energy of a methacrylate adhesive for mining applications, Appl. Adhes. Sci. 3 (1) (2015) 14.

[44] R. Adams, J. Coppendale, V. Mallick, H. Al-Hamdan, The effect of temperature on the strength of adhesive joints, Int. J. Adhes. Adhes. 12 (3) (1992) 185-190.

[45] L.F. Da Silva, R. Adams, Measurement of the mechanical properties of structural adhesives in tension and shear over a wide range of temperatures, J. Adhes. Sci. Technol. 19 (2) (2005) 109-141. 